\title{
COMPUTER SUPPORT IN NON-VERBAL COMMUNICATION SYSTEMS WITH USING GRAPHIC SINGS IN EDUCATION OF PEOPLE WITH INTELLECTUAL DISABILITIES
}

\author{
Konrad Gauda' ${ }^{1}$ Monika Nowosad ${ }^{2}$ \\ 1 Fundamentals of Technology Faculty, Lublin University of Technology, Nadbystrzycka 38, 20-618 Lublin, \\ Poland, e-mail: k.gauda@pollub.pl \\ 2 Special Educational Centre, Kozice Dolne 33, 21-050 Piaski, Poland
}

Received: 2014.09 .25

Accepted: 2014.10.25

Published: 2014.12.01

\begin{abstract}
The article presents the possibility of using a computer with specialized software to support education of students with communication disorders. It also presents the results of preliminary tests based on the original program developed for students with intellectual disabilities in moderate and significant degree of disability in the field of alternative communication with using pictograms and pcs.
\end{abstract}

Keywords: alternative communication, pictograms, intellectual disability.

\section{INTRODUCTION}

A large part of the population is not able to fully communicate with the speech. These are people wholly devoid of the ability to speak, or those whose speech does not meet all the features of communication functions. Therefore, they may need non-verbal means of communication, which would be complementary to or substitute for speech. The problems of people in need of alternative communication are very diverse. For many children whose speech develops over time fades away the necessity of using alternative communication. In the case of people who use this type of communication throughout their lives the understanding of language comprehension and motor skills may willed their entire existence. Speech disorders are very common among students with intellectual disability. This causes significant difficulties in communication, and gives as well as a negative impact on development in all spheres of life, including their ability to acquire knowledge in the educational process. The use of alternative communication gives students the opportunity to expand to a process of communicating, and facilitates the understanding of their statements by others. The particular importances in both the public alternative and complementary systems of communication have different graphics. These systems consist of more or less stylized drawings, which show mostly pictorial similarity to counterparts in reality [8]. An important factor in the selection of appropriate graphics system is primarily the degree of understanding of the language by the child and the ability of its perception of visual sensations. In practice, however, there are brought together different systems but nevertheless using them is closely related to the use of communication support starting from ordinary arrays, and ending with tools based on PC technology. Access to aid communication is particularly important for people with autism, with movement disorders or intellectual disabilities [4].

\section{OVERVIEW OF SELECTED SYSTEMS OF GRAPHIC CHARACTERS}

The first graphic signs which a person with a disability learns are particularly important because they form the basis of the understanding how you can use the characters in the educational 
process. Teaching them is most difficult and takes a lot of time. Making a distinguished selection can greatly facilitate the subsequent process of education. It is very rare that a disabled person is not communicating in a certain way at the start of the study. This is why; when choosing a system of signs we must take into account already existing communication skills. In the world, particularly in the United States, the United Kingdom and the Nordic countries to the most popular systems of graphic characters include: pictograms, PCS symbols, the system Rebus, leksigrams, and Bliss symbols [8]. In Poland, we widely utilize the pictograms, PCS and additionally Makaton system, which is connected to the Rebus system. Although the Bliss system is the most advanced graphic system accessible to persons with nonverbal. However, it is a relatively difficult way of communication and requires special teaching methods. Differences between the symbols are small and difficult to grasp, especially by people with mental disabilities. The system is most fully benefitial for intellectually disabled people with speech and reading difficulties [6].

There is no reason why we could not combine different systems. A limited number of pictograms can sometimes be complemented with the signs coming from the PCS. When the same user predefined the system the choice is not a big problem. In general, PCS and PIC become too limited for many people, and only then Bliss symbols are introduced [5].

\section{Pictograms}

Pictograms (Pictogram Ideogram Communication - PIC) consist of identikit drawings of white silhouettes against black background. Each pictogram contains a verbal description of one word above the figure (Figure 1). Currently, there are 1400 characters PIC [1]. The system compris-

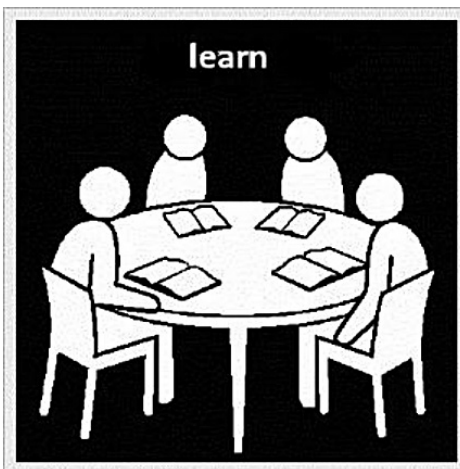

Fig. 1. Example pictogram [1] es several classes of words. The focus is on nouns and verbs, but the system also contains pronouns, adjectives, numerals, conjunctions, prepositions, interjections and adverbs. Pictograms are not a complete system of language (as for example in Polish), but are support in science and communication, both verbal and non-verbal.

Pictograms are considered a sign system friendly and easy to learn. They can be used for lying of whole sentences, but due to the limited number of them is not always a simple task. When the user needs more meanings than those offered by the system are often introduced graphic signs of a more general nature with other systems.

\section{PCS}

PCS (Picture Communication Symbols) is a collection of simple drawings in identifying basic words necessary for daily communication (Figure 2 ). The system consists of 3500 characters - simple black and white (recently introduced a color) line drawings with slogans scrawled above or below the symbols. Symbols are arranged in categories: social, people, verbs, descriptive, food, leisure, and other nouns. Some elements such as articles and prepositions are presented using traditional orthography without the linear image. A characteristic feature of these characters is that they are easily drawn.

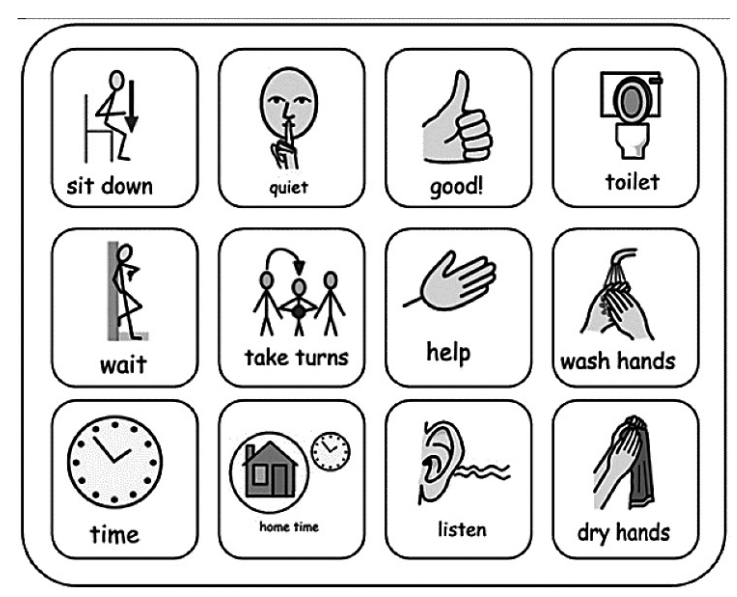

Fig. 2. Example of PCS [2]

PCS is the most common graphic system in the world. Many of the symbols submitted comes in two versions: a fewer and more abstract one, which provides utility system for people who are at different levels of understanding [9].

Polish library of PCS symbols (symbols are labeled with Polish names) contains a com- 
puter Boardmaker program. The library of the program is enriched with new, typically Polish PCS symbols, namely: Polish cuisine, images of famous people, poems and rhymes, holidays, popular sports games, money, etc. Another advantage of this system compared with the PIC is greater than the number of characters [3].

\section{Makaton Symbols}

In Makaton symbols each concept has its corresponding symbol (graphic symbol). The program (Basic) consists of approximately 450 basic symbols and about 7000 symbols supplementing additional. Symbols are always accompanied by correct grammar question (depending on the capabilities of the child / adult). The characters were created (adaptation consists in changing of the image of the certain symbols and creating new ones) in Poland in the years 2001-2003 by Bogusława Kaczmarek. Makaton symbols are black-and-white (black figure, white background) drawings, covering the importance of concepts that they represent (Figure 3). They are characterized by transparency and simplicity, which allows them manually (without having to use a printer) to draw. In addition in Makaton symbols manual sings are also used. These characters are mainly used by children whose parents wish to communicate with them in the pre-verbal stage, when they do not speak yet and the child's natural communication system is gestures.

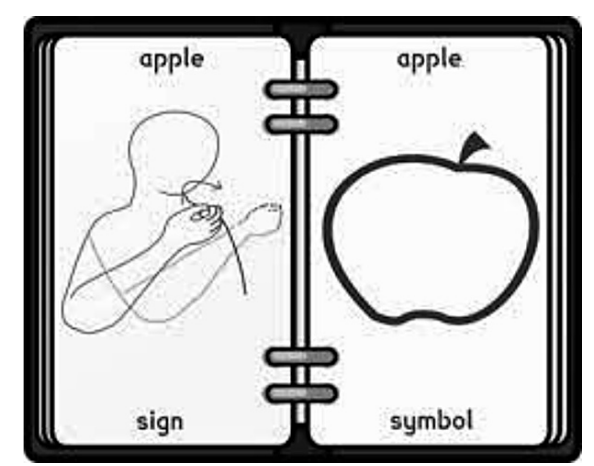

Fig. 3. Example of Makaton graphic symbol with a corresponding sign manual [10]

\section{COMPUTER AIDED PROCESS OF NON-VERBAL COMMUNICATION}

As communication aids we use all kinds of measures that support the expression of the user. Access to them is particularly important for peo- ple with impaired mobility, people with autism who have problems with language and mental disabilities. Most frequently, they are different kinds of plaques, indicators and books with logos or pictures. However, in the era of developing computer technology they are made with modern computer aids both hardware (such as touch screens, switches, keyboard, instant messaging) and pro-speech (e.g. games, speech synthesizers, etc.) (Figure 4) [7].
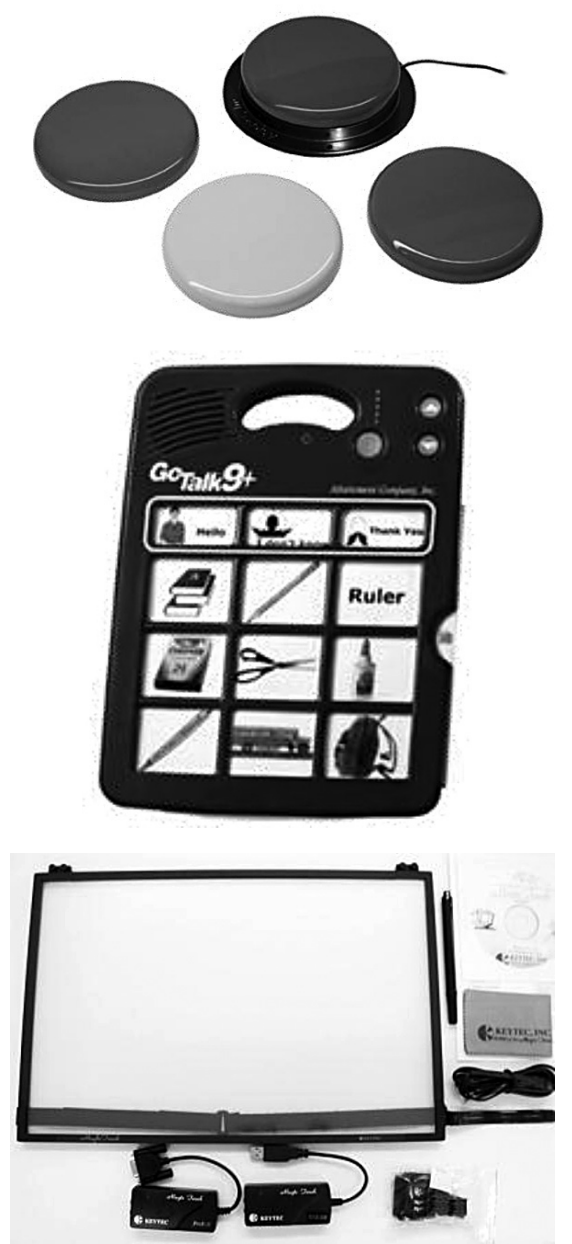

Fig. 4. Examples of hardware supporting communication process [11]: a) AbleNet buttons; b) portable communicator GoTalk - allows you to record up to 45 messages; c) touch screen monitor 17 ”

In the case of people using graphic signs is necessary to introduce a computer program with an appropriate system of signs. On the market today there are several programs that use systems Bliss, PIC, or PCS. An example of this type of program is Boardmaker \& Speaking Dynamically Pro which supports the alternative communication by creating interactive charts, educational materials: sticks, work cards, plans for the day, and task boards with the ability to 
print and use them directly using a computer. The application works with a speech synthesizer, so that messages can be read aloud. In turn, software SymWord is a talking text editor that allows writing the sings by using the supplied program symbols, full of words or letters. SymWord is a tool both for people using buttons or other devices of this type (e.g. de-vice responsive to the blowing and suction), people who do not know letters and communicate with symbols, as well as for people with learning difficulties - for example, dyslexia (Figure 5) [11].

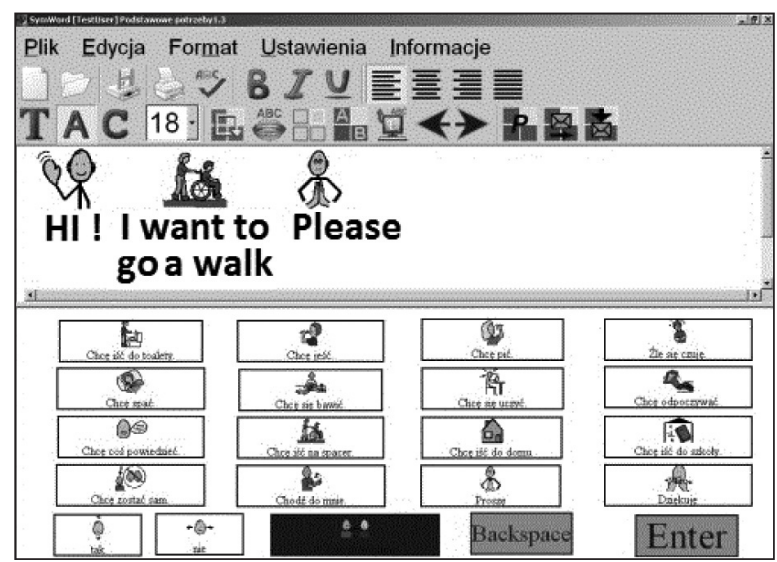

Fig. 5. The SymWord program interface

Other common applications of this type are: Altik, Happy Duck, Puzzle Tile, This pictorial fun with Makaton (Figure 6)

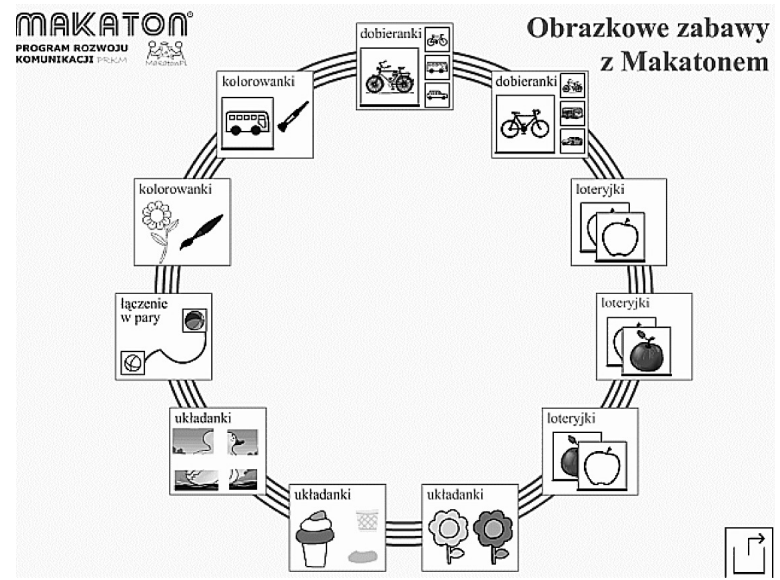

Fig. 6. The program interface this pictorial fun with Makaton

In Poland, in many centers Makaton program is used which uses the PECS strategies (Picture Exchange Communication System The system of communication through the Picture Exchange) for enhancing the effectiveness of teaching graphic symbols.

\section{EXPLORATORY RESEARCH}

\section{Purpose and organization of research}

The aim of the study was to determine the role of specialized classes with the use of computers in teaching alternative communication using pictograms and PCS. The research was conducted at the Special Education Centre in Kozice Dolne. A proprietary curriculum, which was completed within 45 hours individually with each of the three students involved in the study was used (Table 1).

Table 1. Characteristics of examined pupils

\begin{tabular}{|c|c|c|}
\hline Pupil & Age & $\begin{array}{c}\text { The degree of } \\
\text { mental disability }\end{array}$ \\
\hline Mateusz & 5 lat & moderate \\
\hline Karol & 7 lat & substantial \\
\hline Kacper & 7 lat & substantial \\
\hline
\end{tabular}

Introducing the symbols and pictograms pcs we retained a sequence, namely:

- used pictograms and pcs to express "yes" and "no",

- shaped in the concept of "I",

- built the dictionary of the child by placing symbols of things from the nearest surroundings, symbols, names of people, symbols defining characteristics of objects, phenomena,

- the corresponding terms used symbols steps.

Familiarizing the pupils with the words (symbols) was done by performing the following exercise:

- matching, or combining a pictogram or pcs of the concrete,

- matching, or combining a pictogram or pes of illustration,

- combining two of the same pictograms or pcs,

- joining of two identical or pcs pictograms, but of different sizes,

- choosing from two or more pictograms or pes specific-noted by the teacher,

- exercising of understanding the meanings of the symbols through the creation of pictograms or pcs the straight assortment associative (matching objects that match each other with the function, purpose, sorting objects by groups)

- conducting interviews with children on a specific topic; selecting the "words" of pictograms or pcs on the subject. 
There were used when the computer aids such as: Tile Puzzle, pictorial fun with Makaton, Altik, Boardmaker with Speaking Dynamically Pro, SymWord database PCS symbols.

The study began with an initial diagnostic whose aim was to assess up-to-student communication skills, establish contact with students and guarantee them a sense of security. Then we developed the ability to recognize the symbol and receptive communication (recipient) and expressive (sender). The final stage of the research was to perform a final diagnosis, the purpose of which was to check the progress of students after the program implementation and effectiveness of the acquisition of communication skills.

For individual learning outcomes we adopted 7 step scales, where 0 meant you lack of verbal communication skills, and 6 points is a normal development of non-verbal communication. In order to assess the variation in the size of the respondents was introduced K-factor, which was the percentage ratio of the number of points obtained after the implementation of the program of non-verbal communication (final diagnosis Dk) to the number of points obtained after the initial diagnosis (Dw) described in equation (1):

$$
\mathrm{K}=\mathrm{Dk} / \mathrm{Dw} \cdot 100 \%
$$

This factor allows the assessment of the degree of changes in the student's communication skills in relation to their competence prior to testing.

\section{Analysis of test results}

The results of testing are shown in three tables (Table 2-4) and a radar chart (Figures 7-9).

For the second test student - Karol, we also found an increase in communication skills $(\mathrm{K}=$ 194\%). However, this increase is more than twice lower compared to Mateusz. This is due to the fact that these students have ordered different degrees of intellectual disability. Hence, despite the

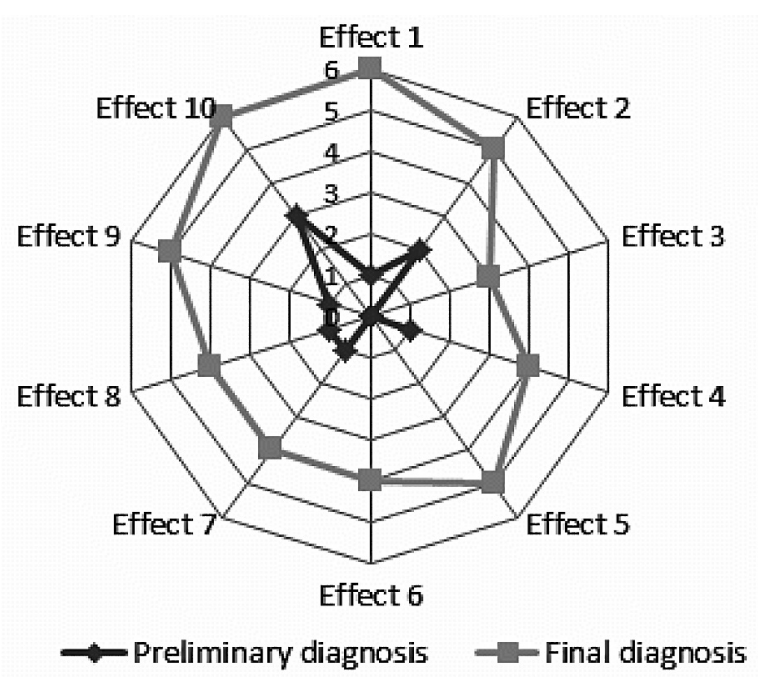

Fig. 7. Graph showing the number of points gained by the student after the initial and final diagnosis, taking into account the different learning outcomes (Mateusz) in the first test student (Mateusz) it can be concluded that the activities of non-verbal communication using computer programs significantly influenced its competences in communication. For all the assumed effects of education can be seen a marked increase in skills ( $\mathrm{K}$ factor $=460 \%$ ).

Table 2. The results of the initial diagnosis after implementation of the program of activities of non-verbal communication (Mateusz)

\begin{tabular}{|c|c|c|c|}
\hline \multirow{2}{*}{$\begin{array}{c}\text { Effect } \\
\text { number }\end{array}$} & \multirow{2}{*}{ Learning outcomes for pupils } & \multicolumn{2}{|c|}{ Mark } \\
\hline & & preliminary diagnosis & final diagnosis \\
\hline 1. & Attempts to communicate non-verbal & 1 & 6 \\
\hline 2. & Has a passive dictionary & 2 & 5 \\
\hline 3. & Has an active vocabulary & 0 & 3 \\
\hline 4. & Understands the situation, gestures, few words, colloquial language & 1 & 4 \\
\hline 5. & Responds to his name & 0 & 5 \\
\hline 6. & Understands the commands and prohibitions & 0 & 4 \\
\hline 7. & Can choose one of the two elements & 1 & 4 \\
\hline 8. & Can adequately and consistently indicate YES & 1 & 4 \\
\hline 9. & Can adequately and consistently indicate NO & 1 & 5 \\
\hline 10. & Has a perceptual capabilities sufficient for the use of graphic symbols & 3 & 6 \\
\hline
\end{tabular}

The rating scale from 0 to 6 , wherein:

0 - the total absence of non-verbal communication skills,

6 - the normal development of non-verbal communication. 
Table 3. The results of the initial diagnosis after implementation of the program of activities of non-verbal communication (Karol)

\begin{tabular}{|c|l|c|c|}
\hline \multirow{2}{*}{$\begin{array}{c}\text { Effect } \\
\text { number }\end{array}$} & \multicolumn{1}{|c|}{ Learning outcomes for pupils } & \multicolumn{2}{|c|}{ Mark } \\
\cline { 2 - 4 } & \multicolumn{1}{|c|}{ preliminary diagnosis } & final diagnosis \\
\hline 1. & Attempts to communicate non-verbal & 3 & 5 \\
\hline 2. & Has a passive dictionary & 2 & 4 \\
\hline 3. & Has an active vocabulary & 0 & 0 \\
\hline 4. & Understands the situation, gestures, few words, colloquial language & 3 & 5 \\
\hline 5. & Responds to his name & 2 & 4 \\
\hline 6. & Understands the commands and prohibitions & 2 & 4 \\
\hline 7. & Can choose one of the two elements & 0 & 2 \\
\hline 8. & Can adequately and consistently indicate YES & 0 & 3 \\
\hline 9. & Can adequately and consistently indicate NO & 4 & 4 \\
\hline 10. & Has a perceptual capabilities sufficient for the use of graphic symbols & 3 & 5 \\
\hline
\end{tabular}

The rating scale from 0 to 6 , wherein:

0 - the total absence of non-verbal communication skills,

6 - the normal development of non-verbal communication

Table 4. The results of the initial diagnosis after implementation of the program of activities of non-verbal communication (Kacper)

\begin{tabular}{|c|l|c|c|}
\hline \multirow{2}{*}{$\begin{array}{c}\text { Effect } \\
\text { number }\end{array}$} & \multicolumn{1}{|c|}{ Learning outcomes for pupils } & \multicolumn{2}{c|}{ Mark } \\
\cline { 3 - 4 } & \multicolumn{1}{|c|}{ preliminary diagnosis } & final diagnosis \\
\hline 1. & Attempts to communicate non-verbal & 1 & 2 \\
\hline 2. & Has a passive dictionary & 1 & 2 \\
\hline 3. & Has an active vocabulary & 0 & 0 \\
\hline 4. & Understands the situation, gestures, few words, colloquial language & 2 & 3 \\
\hline 5. & Responds to his name & 2 & 3 \\
\hline 6. & Understands the commands and prohibitions & 1 & 2 \\
\hline 7. & Can choose one of the two elements & 0 & 1 \\
\hline 8. & Can adequately and consistently indicate YES & 0 & 1 \\
\hline 9. & Can adequately and consistently indicate NO & 0 & 2 \\
\hline 10. & Has a perceptual capabilities sufficient for the use of graphic symbols & 2 & 2 \\
\hline
\end{tabular}

The rating scale from 0 to 6 , wherein:

0 - the total absence of non-verbal communication skills,

6 - the normal development of non-verbal communication.

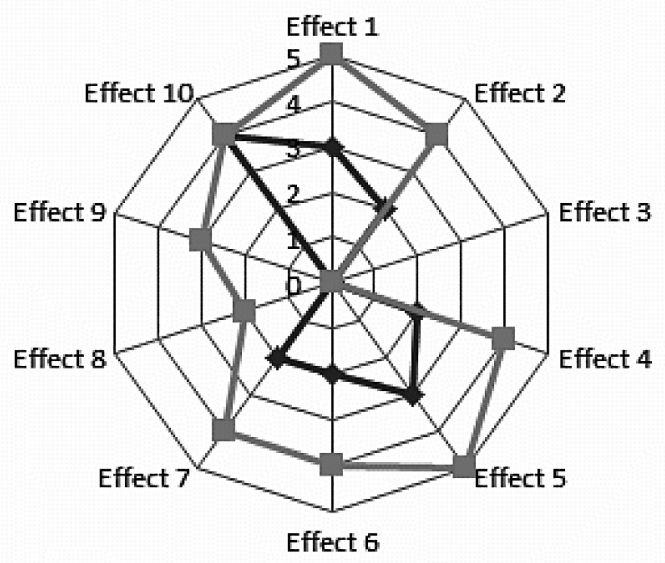

-Prelim inary diagnosis $\quad-$-Final diagnosis

Fig. 8. Graph showing the number of points gained by the student after the initial and final diagnosis taking into account the different learning outcomes (Karol)

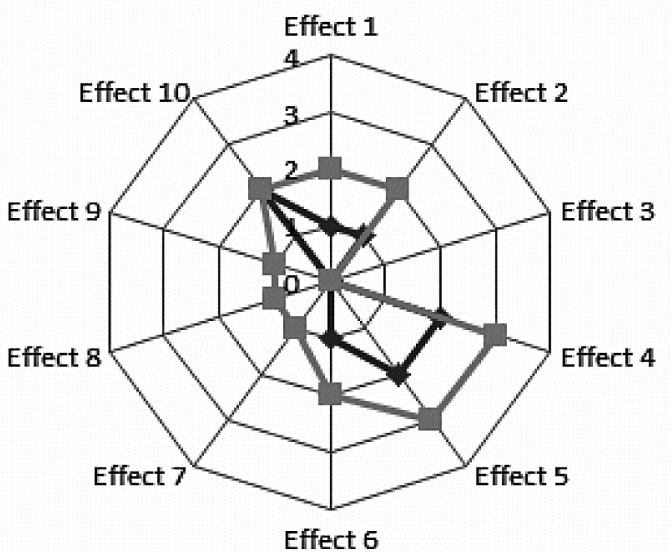

$\multimap$ Prelim inary diagnosis - - Final diagnosis

Fig. 9. Graph showing the number of points gained by the student after the diagnosis of the initial and final taking into account the different learning outcomes (Kacper) 
fact that Karol is older two years from Mateusz achieved lower scores. He needs more time and attention on it to have full communication skills, in particular, to have a dictionary open.

The last of the tested students, Kacper, has the least-developed communication skills, in his case, although there was a slight increase in skills $(\mathrm{K}=188 \%)$.

The reason may be the fact that his perceptual capabilities are at their lowest level among all the surveyed students (a score of 2 points). Through the use of specialized computer programs can be noted that Kacper is more motivated to work longer, he is able to keep focus on the task and take a greater extent to try to agreement with the teacher.

\section{CONCLUSIONS}

Communication is the basis of the knowledge about yourself and the surrounding world by naming objects, phenomena, events, determining their characteristics and relationships between them. Ability to communication is a source of discovering and trying out own skills to influence the environment. It is also one of the main determinants of psychosocial development. When a child does not speak, it does not mean that he does not have anything to say. He sometimes does not know an effective way to engage in dialogue. The need to communicate with the environment is undoubtedly the most important psychological need of every human being. When speech is severely impaired we should help the child to use adequate support or alternative ways of communication.

The results clearly indicate that the main objective of the curriculum realized where students had to provide a means of communication enriching their communication with the environment is achieved. Learning to use pictograms or pcs according to the rules and recommendations of content based on the preferences of child registry. A teacher must create a plan to work with the child. The number of symbols placed in the students is based on their skills, the needs and requirements. The word that fit best child's needs are included in the dictionary. The most appropriate test of students' understanding of the meanings of the pictograms or pcs is their use in natural situations of everyday life at school and at home, even for determining the tasks to be performed, or to obtain from answers to questions. It is also important that parents are involved in the process.

An important place in the educational process of communication skills is occupid bys specialized computer programs. Currently, they are indispensable aids so that the teacher can easily create a variety of communication boards, plates, cards work or plans of the day. High interactivity applications of this type make the student does not feel the hardships arduous process of education or rehabilitation and eager to participate in the classes. These programs implement the principle of ludic which is extremely important for the youngest pupils. With the creative use of computer programs significantly increases the efficiency of education - developing thinking cause-and-effect relationships and communication skills. The results are achieved in less time than in case when using traditional methods.

\section{REFERENCES}

1. Brzegowa A.: Metody komunikacji alternatywnej i wspomagającej AAC - piktogramy. (www.edukacja.edux.pl - 15.05.2014).

2. Glennen S. (ed.): The handbook of augmentative and alternative communication. Singular Pub. Group, San Diego 1997.

3. Grycman M., Kaniecka K., Szczwiński P.: PCS. Stowarzyszenie Mówić bez słów, Kraków 2001.

4. Morris D.: Dictionary of Communication Disorders. Chichester Wiley 2013.

5. Orkan-Łęcka M.: Wczesne wspomaganie rozwoju komunikacji u dzieci niewidomych i słabo widzących ze złożoną niepełnosprawnością - model programu edukacyjnego. Rewalidacja nr 2, 1999.

6. Posner R., Burkhardt A., Ungeheuer G., Wiegand H., Steger H.: Handbücher zur Sprach und Kommunikationswissenschaft. Walter de Gruyter, Berlin 2004.

7. Quist R., Lloyd L.: Principles and use of technology. [In:] Lloyd L., Fuller D., Arvidson H.: Augmentative and alternative communication. A handbook of principles and practices. Allyn and Bacon, Boston 1997.

8. Tetzchner S., Martinsen H.: Introduction to augmentative and alternative communication. 2nd edition, Wiley 2000.

9. Warrick A.: Porozumiewanie się bez słów, Stowarzyszenie Mówić bez stów, Warszawa 1999.

10. www.makaton.pl (17.05.20014)

11. www.harpo.com.pl (25.05.2014) 